\title{
Körner's septum (petrosquamosal lamina): the anatomical variant or clinical problem?
}

\author{
T.T. Przewoźny ${ }^{1}$, A. Kosiński², K. Markiet ${ }^{3}$, W. Sierszeń1 ${ }^{1}$ J. Kuczkowski', \\ J. Kuryłowicz ${ }^{1}$, A. Skorek ${ }^{1}$ \\ ${ }^{1}$ Department of Otolaryngology, Medical University of Gdansk, Poland \\ ${ }^{2}$ Department of Clinical Anatomy, Medical University of Gdansk, Poland \\ ${ }^{3} 2^{\text {nd }}$ Department of Radiology, Medical University of Gdansk, Poland \\ [Received: 1 April 2019; Accepted: 7 July 2019]
}

\begin{abstract}
Körner's septum (KS) or petrosquamosal lamina is a bony lamina beginning at the articular fossa, extending above the middle ear, and running inferiorly and laterally to the facial nerve canal as it proceeds to the mastoid apex. This septum marks the junction of petrous and squamous bones. The paper presents details of the anatomical structure of $\mathrm{KS}$, which is most often present at the level of the head of the malleus and/or the anterior semicircular canal. Attention is paid to embryological aspects of temporal bone development that lead to the formation of KS. Two imaging techniques most frequently used to diagnose KS are described, high resolution computed tomography (HRCT) and cone-beam computed tomography. Also presented is a case report of a 6-year-old patient suffering from chronic otitis media who developed a cholesteatoma due to presence of KS, illustrated with HRCT images and intraoperative capture. The authors describe diagnostic difficulties associated with this anatomical variant in the middle ear. The article also discusses the more frequent occurrence of this clinical problem in ears operated on due to chronic inflammation, retraction pocket or tympanosclerosis in comparison to healthy ears. (Folia Morphol 2020; 79, 2: 205-210)
\end{abstract}

Key words: Körner's septum, petrosquamosal lamina, temporal bone, otosurgery

\section{INTRODUCTION}

Körner's septum (KS) is an osseous lamina located within the temporal bone separating air cells of the mastoid. KS was first reported on by Hartmann in 1887 as a thin bony wall situated between antrum petrosum and antrum mastoideum. Its presence has been described subsequently by further researchers; however, it was not until Körner [7] that the clinical significance of the septum was raised. Spectacular development of the temporal bone surgery caused increased interest into KS. Shulman and Rock [14] stated that a prominent KS may be mistaken for the bony lamina covering the sigmoid sinus. Nowadays some authors underline the risk of misinterpreting the KS for the medial wall of the antrum $[4,10,13]$.

\section{ANATOMY AND EMBRYOLOGY}

Körner's septum is located at the junction of the petrous and squamous parts of the temporal bone and thus is treated as a part of the of the petro-squamosal suture. According to literature the petro-squamosal suture consists of three parts, their nomenclature varying amongst publications $[12,16$, 19]. Classification proposed by Virapongse et al. [16] is the most commonly used. According to which anterior (ventral), middle and posterior (dorsal) parts 


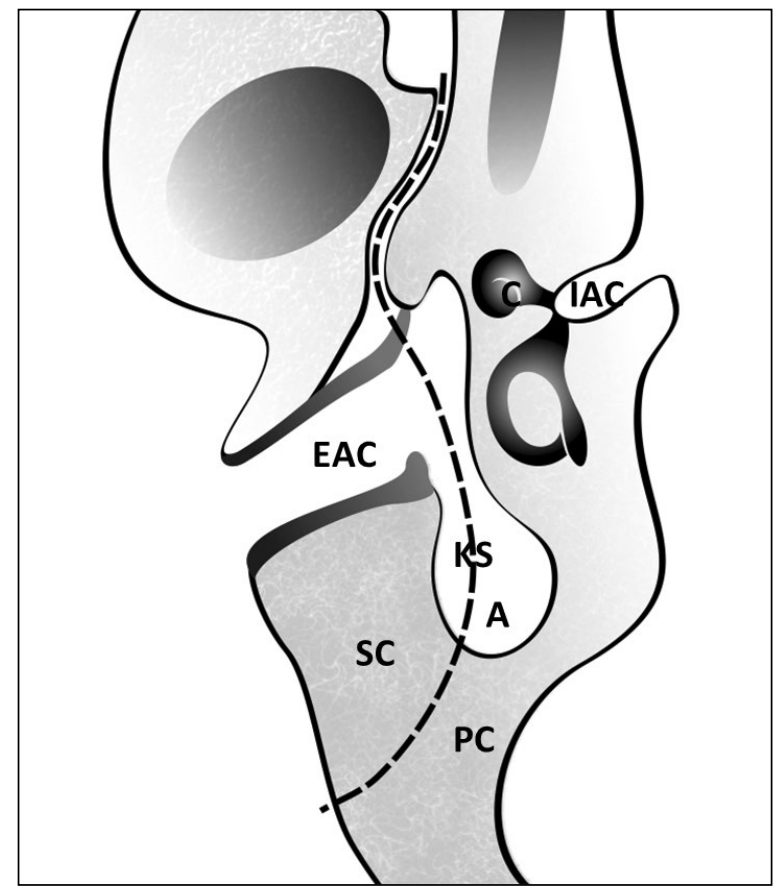

Figure 1. Development of the mastoid process from the squamous and petrous bones. Persistence of petrosquamosal suture as a bony plate (Körner's septum [KS]); EAC - external auditory canal; IAC - internal auditory canal; A - antrum; C - cochlea; SC squamous cells; $P C$ - petrosal cells.

are distinguished. Also cog, a bony ridge in the epitympanum, is perceived as a part of the KS (middle/ tympanic part) (Fig. 1).

Körner's septum extends from the posterior part of the mandibular fossa (from the petrosquamosal fissure), courses over the middle ear cavity (slightly aslant — from the front and side, in the posterior-medial direction, within the tegmental wall), directing downwards, laterally to the facial nerve canal (in its vertical - mastoid part) and into direction of the mastoid apex. It ends on the anterolateral surface of the lower part of the mastoid process. Its posterior part divides mastoid cells into deep and superficial groups.

Research reveals the continuity of KS may be disrupted in more than one point $[9,12,19]$. In reference to anatomical landmarks the septum is most frequently seen at the levels of the head of the malleus and the superior semicircular canal, while most seldom at the level of the tympanic sinus [11]. Unfortunately, it remains unknown whether the discontinuity of the septum results from developmental anomalies or damage in course of disease.

Thickness of the septum varies both with sex and location. According to Avci et al. [2], it is significantly thicker in males. Wojciechowski et al. [19] further noted that KS is the thickest at the level of the malleus head, the thinnest at the level of the tympanic sinus. Research indicates that the form of KS is not mandatory correlated to the size of the mastoid part of the temporal bone. However, greater thickness of the septum may be correlated to less developed pneumatisation of the mastoid.

Interpretation of the complex morphology of the KS may be facilitated by embryological knowledge. The petrous part of the temporal bone - contrary to the squamous part - develops on a cartilaginous base. Its ossification begins late, at around 16 weeks of pregnancy, but is intense. At 24 weeks of pregnancy a thin bony lamina distinguishes from the lateral aspect of the petrous part of the temporal bone crossing over the area of primary middle ear in the direction of analogical structure deriving from the squamous part. The petro-squamosal suture results from their junction. Additionally, the petrosal portion plays a more important role than the squamosal portion in pneumatisation of the temporal bone [5]. For yet unknown reason its posterior part translocates downwards and thus KS also develops in an oblique plane, directing downwards.

Körner's septum corresponds to persistent petro-squamosal suture and divides mastoid cells into medial and superficial parts $[5,14]$. Analysis of high resolution computed tomography (HRCT) examinations of the temporal bone shows its similar prevalence on both sides, with a predilection to males, which may be partially explained by larger thickness of the septum in males in comparison to females $[2,19]$. According to Wojciechowski et al. [19] KS consists of three parts: anterior (the most constant, identified at the level of head of malleus), superior (identified at the level of superior semicircular canal) and posterior (the least constant, at the level of tympanic sinus). Due to the fact that KS may vary in form and/or present with discontinuities/disruptions, some authors suggest that the tympanic part of the septum (midportion) is an osseous ridge called cog $[10,16]$. The cog is localised within the superior wall of the tympanic cavity and divides the epitympanum into two parts: the posterior part and the anterior part, also known as supratubal recess. Interestingly, in all patients who had cogs, there was also KS at the mastoid antrum [10]. The middle part of the septum is responsible for decreased ventilation of the tympanic cavity between protympanum and antrum leading to development of inflammatory processes. 


\section{DIAGNOSTIC IMAGING OF KÖRNER'S SEPTUM}

Körner's septum can be best visualised in HRCT and cone-beam computed tomography (CBCT) of the temporal bone $[8,9,15,19]$. In HRCT, data acquisition is routinely performed in axial plane, parallel to lateral semicircular canal with standard coronal reconstructions [8]. The field of view is contained between the level of superior mastoid cells and the upper wall of external auditory canal and the level of the stylomastoid foramen. Images of both temporal bones in soft tissue window are obtained with slice thickness of 1.0-1.25 mm allowing assessment of soft tissues adjacent to the bone and the posterior fossa, followed by bone window reconstructions of each of the temporal bones separately with slice thickness not exceeding $1 \mathrm{~mm}$ (it usually ranges $0.4-0.6 \mathrm{~mm}$ ). HRCT of the temporal bones is routinely performed without contrast agent administration. Multiplanar reconstructions are applied including reconstructions in Poschl plane (parallel to superior semicircular canal), in Stenvers plane (perpendicular to superior semicircular canal) and the double-oblique plane to visualise the stapes and the oval window. Cochlear implants and middle ear prostheses are not considered contraindications to HRCT imaging; however, they can cause artefacts of the beam hardening and scattering and thus limit the diagnostic value of examination.

Cone-beam computed tomography is becoming an alternative imaging method to conventional CT examination [11]. It uses a rotating gantry on which an X-ray tube and detector are attached. A cone-shaped X-ray beam passes through the middle of the temporal bone onto a two-dimen-

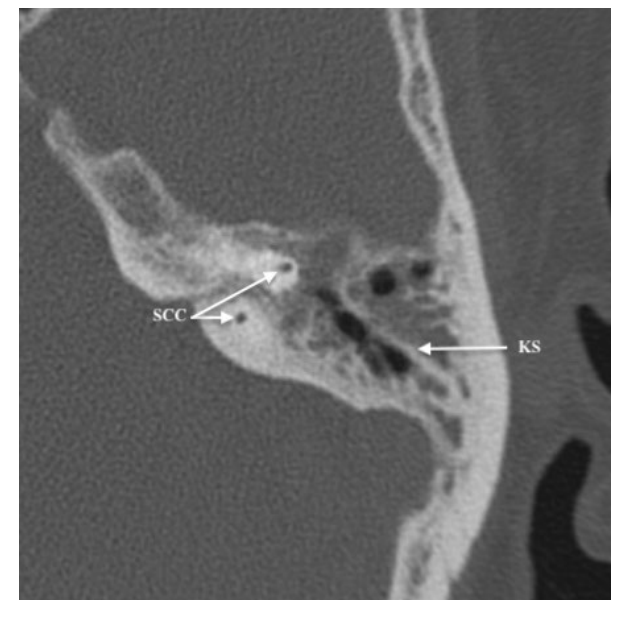

Figure 2. High resolution computed tomography of the left temporal bone, axial plane of a 26 -year-old patient referred for examination with suspicion of chronic otitis media. Körner's septum (KS) at the level of superior semicircular canal (SCC). Signs of otitis media are present.

sional (2D) X-ray detector. A single $360^{\circ}$ gantry rotation is necessary to acquire a volumetric data set allowing further multiplanar reconstructions with slice thickness in range of $0.3-1 \mathrm{~mm}$ using dedicated software [8]. The advantages of CBCT include shorter examination time, high spatial resolution, lower radiation dose and lower sensitivity for metallic and beam hardening artefacts. The most significant limitations include higher sensitivity to motion artefacts - patient is required to hold the head perfectly still during the acquisition time of 40-50 s - and limited possibility of evaluation of the soft tissues. Motion artefacts can be to some extent prevented by using a scanner with a supine patient position (Figs. 2-4).

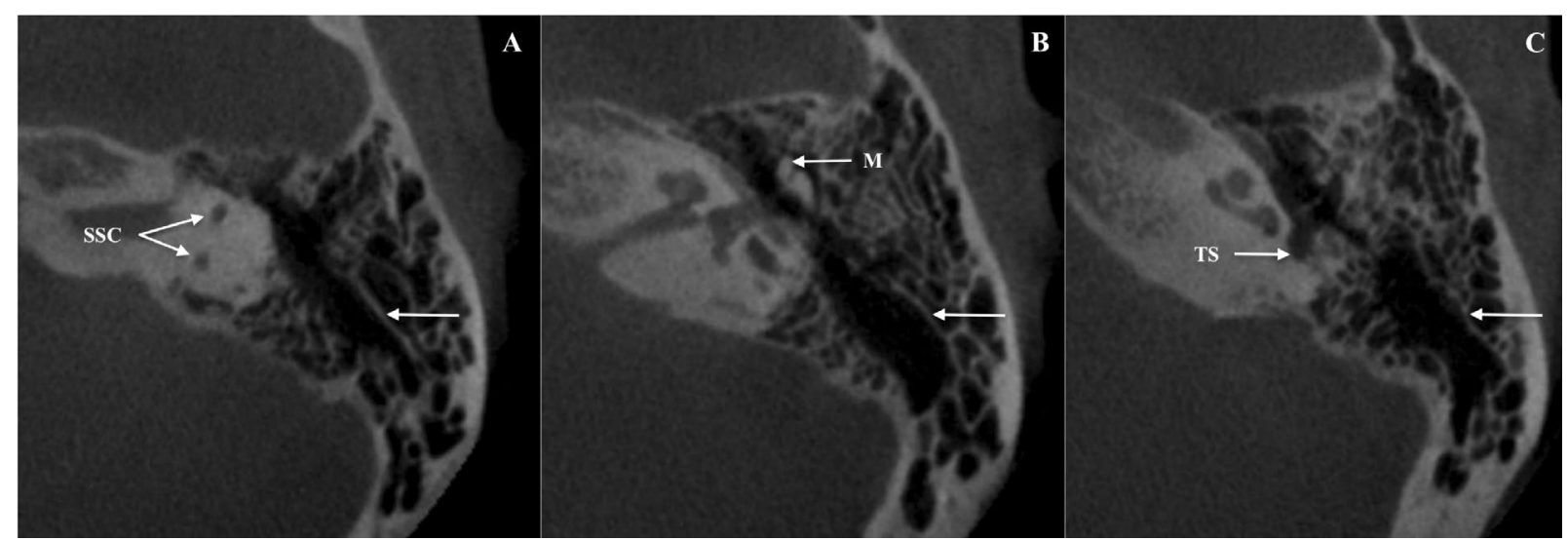

Figure 3. Cone-beam computed tomography of the left temporal bone, axial plane in a 15-year-old patient with headache shows Körner's septum (arrow) at the levels of superior semicircular canal (SSC) (A), malleus head (M) (B), tympanic sinus (TS) (C). 


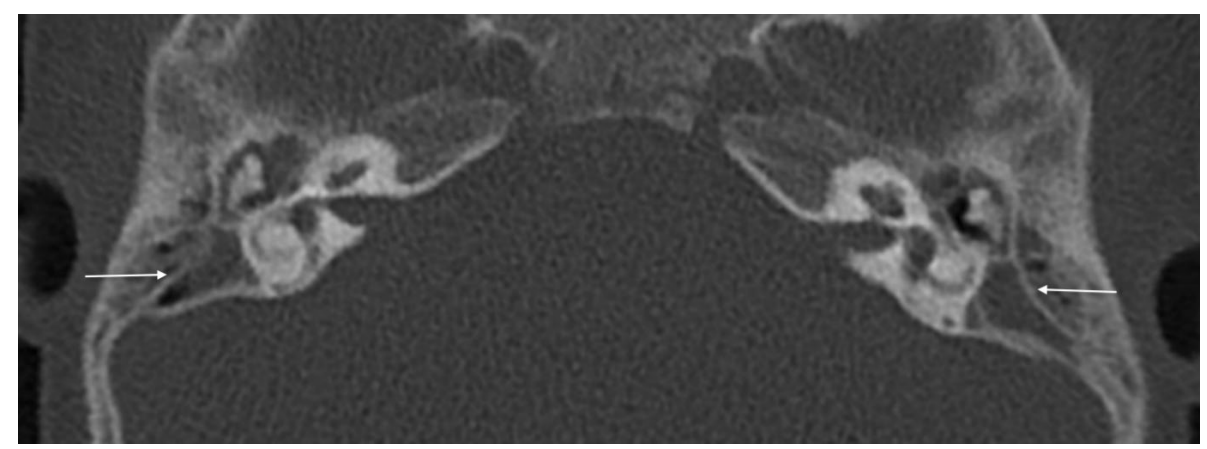

Figure 4. Computed tomography of paranasal sinuses, axial image, depicts the presence of bilateral Körner's septi (arrows) in a 2-year-old patient with pansinusitis and bilateral otitis media.

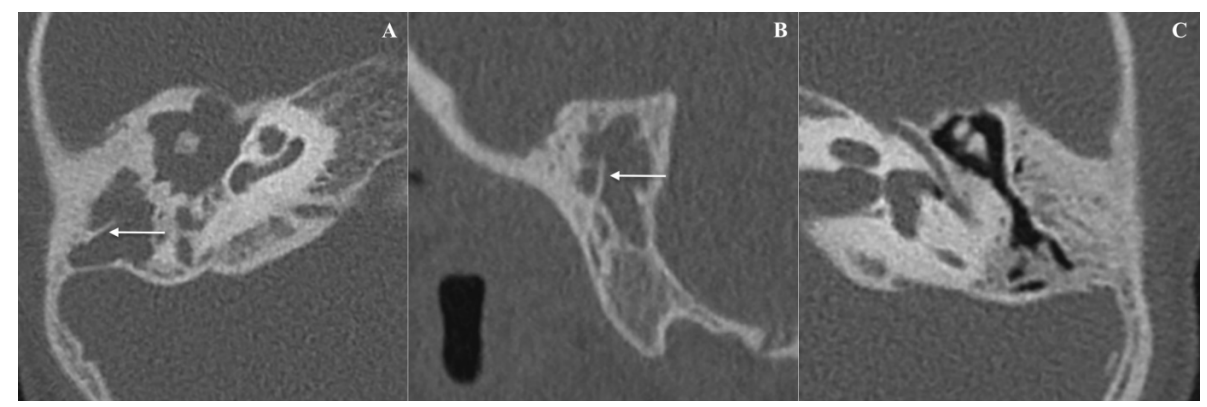

Figure 5. High resolution computed tomography of the temporal bones in a 6-year-old patient with right chronic otitis media; A. Right ear, axial plane at the level of demineralised head of malleus. Arrow points to the partial Körner's septum. Incus is not present; B. Right ear, sagittal reconstruction. Arrow points to the partial Körner's septum; C. Left temporal bone, axial plane. Sclerotic mastoid.

\section{CASE REPORT}

A case of a 6-year-old male patient with chronic cholesteatomatous otitis media is presented. Patient was born prematurely (32 week of pregnancy) with a low body weight of $1840 \mathrm{~g}$ and Apgar score at birth of 3 points. He was operated on for the first time at the age of 4. A closed tympanomastoidectomy with bony obliterative technique and type 3 tympanoplasty according to Wullstein classification. During the procedure the mastoid was opened and a an anterior course of the sigmoid sinus and low position of the dura of the posterior cranial fossa were observed as well as cholesteatoma filling the mastoid, tympanic cavity with infiltration of the Eustachian tube. Destruction of the oval window suprastructure, incus and the head of the malleus was seen. Posterior tympanotomy was performed with removal of the cholesteatoma. A long columella tympanoplasty with malleus repositioning was done; tympanoplastic lobe derived from temporal fascia was administered. Mastoid was obliterated with bone patte, bone debris and tissue glue. Due to complete lack of cooperation from the patient (emphasized also by mild mental impairment), change of ear dress-

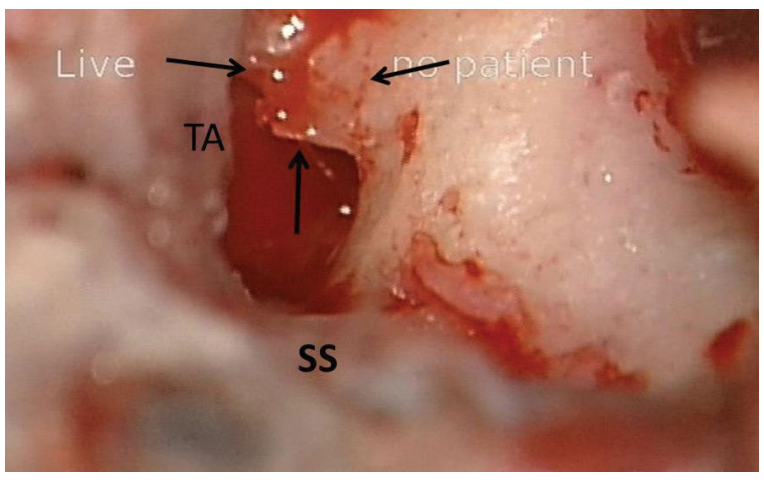

Figure 6. Intraoperative view of the middle ear in a 6-year-old patient with recurrent cholesteatoma with Körner's septum (within arrows); SS — sigmoid sinus; TA — tegmen antri; magnification $\times 10$.

ings required anaesthesia. Recurrence of cholesteatoma was suspected 1.5 year post surgery and confirmed in HRCT. HRCT showed a presence of a partial KS on the operated side (Fig. 5). An open re-tympanoplasty was performed. During the procedure a presence of KS which was not entirely drilled in the first intervention. Under KS cholesteatoma and inflammatory tissue were found and subsequently removed (Fig. 6). 
During the surgery the posterior wall of the osseous part of the external auditory canal was removed, opening external auditory canal into the post antromastoidectomy cavity. Surgery was completed with implementation of a titanium prosthesis on the foot of the stapes; tympanic cavity was covered with a temporal fascia tympanoplastic flap. Patient has been now 6 months in follow-up with no recurrence.

\section{CLINICAL RELEVANCE OF KÖRNER'S SEPTUM}

Körner's septum may constitute a significant clinical problem. During antromastoidectomy, in both isolated surgery and in course of more complex intervention, it resembles a false medial wall of the antrum and the epitympano-mastoid canal [10,13]. If $\mathrm{KS}$ is not opened during exploration of the antrum, a closed space remains within the pneumatised part of the temporal bone that may cause inflammation and recurrence of the chronic otitis media.

It also plays a significant role in reference to middle ear surgery as an increased risk of leaving residual cholesteatoma in the posterior part of the epitympanum, covered by the cog, is observed. Thus performing mastoidectomy with anterosuperior tympanotomy is advised in case of wide KS [10]. Also co-existing anatomical anomalies such as infantile mastoid, sigmoid sinus located close to the ear canal, like in the case we presented, and hypoplastic antrum have been reported in patterns with prominent KS [4]. However, there is no correlation between the size of $\mathrm{KS}$ and mastoid pneumatisation in HRCT analysis [1].

Prevalence of KS varies from $6.5 \%$ to $47 \%$ (mean $32.8 \%)[1,4,19]$ in both healthy patients and in patients treated with surgery due to inflammatory processes. Karaca et al. [6] reported the presence of KS in $28 \%$ of 356 ear that underwent tympanoplasty, Toros et al. [15] $24 \%$ of operated temporal bones. These observations were not confirmed by Göksu et al. [4] who described the prevalence of KS in $6.58 \%$ of healthy ears in comparison to $30.4 \%$ in ears with retraction pocket and/or tympanic membrane adhesion and $17.4 \%$ in cases of chronic otitis media without retraction pocket. On the other hand in data provided by Göksu et al. [4] 54\% of ears with KS showed presence of retraction pockets, while they were also noted in $36 \%$ in healthy ears.

Presence of partial KS, as in our case, was seen in $25-33 \%$ of examined temporal bones $[4,19]$. There are hypotheses that a developing cholesteatoma through reaction of proteolytic enzymes with the perimatrix may lead to partial destruction of KS and paradoxically increase the pneumatisation of the ear simultaneously slowing down the formation of retraction pockets and tympanoslerosis. Obstruction of ventilation of the antrum and/or antrum and epitympanum caused by the presence of $\mathrm{KS}$, is more often encountered in cases of tympanosclerosis with adhesive otitis media than in chronic otitis media with or without cholesteatoma. Moreover KS is more often reported in case of tympanoslerosis than any other form of chronic otitis media [10]. In light of this data KS may cause obstruction of ventilation between protympanum and antrum as well as between antrum and the remaining mastoid cells leading to chronic inflammation.

\section{STRENGTHS AND WEAKNESSES OF PREVIOUSLY PUBLISHED STUDIES}

Potential limitations of our study include the relatively small number of patients limiting the strength of our analysis. Part of the KS references is based solely on the radiological material gives us an idea of how often and in what extent occurs in the temporal bone of a healthy human [1, 3, 17-19]. In our work, we wanted to point the influence of KS on the formation of pathologies such as cholesteatoma and granulation in the middle ear spaces. The works comparing the radiological images with the intraoperative image and showing the incidence of inflammatory diseases of the ear with KS are particularly valuable for the otosurgeon $[4,6,15]$. Some of the surveys depends on formalin-preserved and frozen adult human temporal bones [13] or try to correlate KS with other congenital deformities of the ear.

\section{SUMMARY}

The reasons of forming of KS in second/third trimester of pregnancy by displacement of the squamous part of developing temporal bone are yet unknown. There is, however, reliable research data and significant number of clinical case reports confirming the influence of KS presence on the increased risk of occurrence of inflammatory middle ear processes such as cholesteatoma, retraction pocket and tympanosclerosis most probably due to decreased ventilation of middle ear cavities. Thorough pre-surgical imaging diagnostics of the temporal bones by means of HRCT and/or CBCT is of the utmost clinical importance. These examinations allow otolaryngological surgeons to assess the presence of KS and in case 
of present KS to classify it as a complete or partial septum. Nevertheless further research is required on the influence of $\mathrm{KS}$ being a developmental variation and a significant clinical problem on natural history of middle ear inflammatory processes.

\section{REFERENCES}

1. Aslan A, Mutlu C, Celik O, et al. Surgical implications of anatomical landmarks on the lateral surface of the mastoid bone. Surg Radiol Anat. 2004; 26(4): 263-267, doi: 10.1007/s00276-004-0235-1, indexed in Pubmed: 15205917.

2. Avci $S$, Ergun $T$, Aydin $E$, et al. Sex differences in adult craniofacial parameters. Surg Radiol Anat. 2015; 37(9): 1069-1078, doi: 10.1007/s00276-015-1477-9, indexed in Pubmed: 25935592.

3. Avci S, Ergun T, Aydin E, et al. Craniofacial measures of chronic otitis media patients by 2D reformatted CT. Clin Anat. 2010; 23(4): 374-385, doi: 10.1002/ca.20967, indexed in Pubmed: 20235166.

4. Göksu N, Kemaloğlu YK, Köybaşioğlu A, et al. Clinical importance of the Korner's septum. Am J Otol. 1997; 18(3): 304-306, indexed in Pubmed: 9149822.

5. Hentona H, Okubo J, Tanaka H, et al. [The volume ratio between squamosal and petrosal air cells divided by Körner's septum]. Nihon Jibiinkoka Gakkai Kaiho. 1995; 98(8): 1278-1284, doi: 10.3950/jibiinkoka.98.1278, indexed in Pubmed: 7472765.

6. Karaca CT, Toros SZ, Noşeri H. Analysis of anatomic variations in temporal bone by radiology. Int Adv Otol. 2012; 8(2): 239-243.

7. Körner O. Das Septum petrosquamosum (mastoideum) und seine klinische Bedeutung. Fortschr Hals Nasen Ohrenheilkd. 1926; 17: 137-140.

8. Lemmerling $\mathrm{M}$, De Fo, Smet B. Temporal Bone Imaging Techniques. In: Lemmerling M, De Foer B. ed. Temporal Bone Imaging. Springer-Verlag, Berlin Heidelberg 2015: 7-10.

9. Leng $T$, Zhao $S$, Liu Z, et al. [Korner's septum and congenital aural atresia]. Lin Chuang Er Bi Yan Hou Ke Za Zhi. 2005; 19(10): 436-438, indexed in Pubmed: 16108317.
10. Ozer E, Bayazit YA, Kara C, et al. Körner's septum (petrosquamosal lamina) and chronic ear disease. Surg Radiol Anat. 2004; 26(2): 118-121, doi: 10.1007/s00276-0030186-y, indexed in Pubmed: 14586561.

11. Penninger RT, Tavassolie TS, Carey JP. Cone-beam volumetric tomography for applications in the temporal bone. Otol Neurotol. 2011; 32(3): 453-460, doi: 10.1097/ MAO.0b013e31820d962c, indexed in Pubmed: 21307814.

12. Proctor $B$, Nielsen $E$, Proctor $C$. Petrosquamosal suture and lamina. Otolaryngol Head Neck Surg. 1981; 89(3 Pt 1): 482-495, doi: 10.1177/019459988108900325, indexed in Pubmed: 6791114.

13. Puricelli MD, Newby MD, Fishman AJ, et al. The Petrosquamous Stalactite. Otolaryngol Head Neck Surg. 2017; 156(3): 549-553, doi: 10.1177/0194599816679943, indexed in Pubmed: 28140829.

14. Shulman A, Rock EH. Korner's (petrosquamous) septum in otology. Report of five cases. Arch Otolaryngol. 1972; 96(2): 124-129, doi: 10.1001/archotol.1972.00770090198006, indexed in Pubmed: 5081916.

15. Toros SZ, Karaca CT, Habeşoğlu TE, et al. Is there a relation between mastoid aeration and Körner's septum? Eur Arch Otorhinolaryngol. 2010; 267(10): 1523-1526, doi: 10.1007/s00405-010-1277-0, indexed in Pubmed: 20480369.

16. Virapongse C, Kirchner JC, Sasaki C, et al. Computed tomography of Körner's septum and petrosquamosal suture. Arch Otolaryngol Head Neck Surg. 1986; 112(1): 81-87, doi: 10.1001/archotol.1986.03780010083016, indexed in Pubmed: 3940517.

17. Virapongse $C$, Rothman SL, Kier EL, et al. Computed tomographic anatomy of the temporal bone. Am J Roentgenol. 1982; 139(4): 739-749, doi: 10.2214/ajr.139.4.739, indexed in Pubmed: 6981936.

18. Virapongse C, Sarwar M, Bhimani S, et al. Computed tomography of temporal bone pneumatization: 2. Petrosquamosal suture and septum. Am J Neuroradiol. 1985; 6(4): 561-568, indexed in Pubmed: 3927672.

19. Wojciechowski T, Skadorwa T, Drożdż A, et al. The radioanatomical assessment of the Körner's septum. Surg Radiol Anat. 2019; 41(6): 669-673, doi: 10.1007/s00276-0182149-3, indexed in Pubmed: 30539206. 